\title{
An Analysis of the Prevalence of Heat Waves in the United States between 1948 and 2015
}

\author{
EVAN M. OSWALD \\ Innovim, LLC, and NOAA Climate Prediction Center, College Park, Maryland
}

(Manuscript received 3 October 2017, in final form 20 February 2018)

\begin{abstract}
Unusually hot weather is a major concern to public health as well as other systems (e.g., ecological, economical, energy). This study utilized spatially continuous and homogenized observational surface climate data to examine changes in the regularity of heat waves in the continental United States. This included the examination of heat waves according only to daytime temperatures, nighttime temperatures, and both daytime and nighttime temperatures. Results confirmed a strong increase in the prevalence of heat waves between the mid-1970s and the dataset end (2015), and that increase was preceded by a mild decrease since the dataset beginning (1948). Results were unclear whether the prevalence of nighttime or simultaneous daytime-nighttime heat waves increased the most, but it was clear that increases were largest in the summer. The largest gains occurred in the West and Southwest, and a "warming hole" was most conspicuous in the northern Great plains. The changes in heat wave prevalence were similar to changes in the mean temperatures, and more so in the daytime heat waves. Daytime and nighttime heat waves coincided with one another more frequently in recent years than they did in the 1970s. Some parts of the United States (West Coast) were more likely than other parts to experience daytime and nighttime heat waves simultaneously. While linear trends were not sensitive to the climate dataset, trend estimation method, or heat wave definition, they were mildly sensitive to the start and end dates and extremely sensitive to the climate base period method (fixed in time or directly preceding any given heat wave).
\end{abstract}

\section{Introduction}

Heat waves are a substantial concern to the United States. This was evidenced by the passing of the Weather Research and Forecasting Innovation Act of 2017 (Public Law 115-25; H.R. 353), which directed the NOAA/National Weather Service (NWS) to prioritize subseasonal forecasts of heat waves. Heat waves are damaging to infrastructure (McGregor et al. 2007), stressors of agriculture ( $\mathrm{Gu}$ et al. 2008) and livestock (Mader 2003; Howden and Turnpenny 1997; Reeves and Bagne 2016), and burdens on several systems ranging from ecological (Smith 2011) and public health (Knowlton et al. 2009) to energy (Isaac and van Vuuren 2009). According to the U.S. National Hazard Statistics of the NWS (http://www.nws. noaa.gov/om/hazstats.shtml), "heat" is a leading cause of weather fatalities. A well-known 1995 heat wave increased the number of deaths by $147 \%$ (over normal) in Chicago (Whitman et al. 1997), and a 44-day long heat wave in 2010 in the city of Moscow, Russia, increased the number of

Corresponding author: Evan M. Oswald, evan.oswald@noaa.gov deaths by $83 \%$ over that period ( 11000 excess deaths; Shaposhnikov et al. 2014). Deaths related to heat are more likely to occur within vulnerable sectors of the population such as minorities, the elderly, the young, those taking certain medications, the economically disadvantaged, and the socially isolated (Bao et al. 2015). Fortunately, heat health warning systems have been shown to be highly effective in mitigating impacts on public health (Lowe et al. 2011; Toloo et al. 2013).

Global temperatures in the twentieth and twenty-first centuries have generally been increasing (Hansen et al. 2012). The earlier part of the twentieth century was a warming period (Knappenberger et al. 2001), and the middle portion (1940-69) was a mild cooling period (Menne et al. 2009; DeGaetano and Allen 2002). Since then, steady warming has occurred (Knappenberger et al. 2001; Hansen et al. 2012; Rohde et al. 2013a). The bulk of the warming since the 1970s was manifested in a decrease in the cold-tail temperature extremes (Meehl et al. 2009), high-latitude warming (Cohen et al. 2014), and nighttime and winter warming (Wang et al. 2009). However, the frequency of hot weather during the warm 
season has also been increasing (Peterson et al. 2013). A general increase in the frequency of extremely hot temperatures during the recent warming period is well agreed upon, but variability in the literature of the spatial pattern exists due to the sensitivity to time period, meteorologi$\mathrm{cal} /$ biometeorological variables, daily extrema and/or hot weather definition, statistical methodology, climate data utilized, and time of year.

Notably, the United States has what is termed a "warming hole" in its interior, varying from the northern Great plains and middle Mississippi Valley to the southeastern United States (excluding Florida) depending on the time period, time of year, and daily extrema (Robinson et al. 2002; Wu et al. 2012; Meehl et al. 2012; Oswald and Rood 2014). The warming hole is most pronounced in the winter. The exact combination of mechanisms causing the U.S. warming hole is unsettled, but it likely involves changes in low-level temperature flux convergence (Meehl et al. 2012), the Great plains low-level jet (Pan et al. 2004), and Pacific Ocean sea surface temperatures (Robinson et al. 2002).

Most examinations of the large-scale historical changes in heat waves diagnose heat waves based on percentile threshold exceedence (Grotjahn et al. 2016). Percentiles, as opposed to absolute temperatures, allow for what qualifies as "unusually hot" to vary spatially and therefore accommodate the human aspect of acclimatization to their climates. For this reason, absolute thresholds are more likely to be utilized in regional and local studies. Percentiles quantify how a given temperature relates to past temperatures, usually a 30 -yr period called the "climate base." All known studies regarding heat wave trends that utilize percentiles hold this period constant in time. This is done in order to establish a reference by which an examination of temporal change is possible. Conversely, the climate base period should be as relevant as possible to any given year since the percentiles are supposed to reflect what the population is accustomed to experiencing-in other words, the years that directly preceded the heat wave. Percentiles based on such a climate base period would therefore account for what the population is accustomed to experiencing both spatially as well as temporally.

The benefits of understanding changes in heat waves are not limited to the summer season (June-August). Nonetheless, most studies scrutinize the past changes in hot weather either in the summertime or all year around. While the summer is the time of year associated with human health impacts, heat waves during other seasons also have impacts. For instance, heat waves in the late spring are of particular interest to public health officials (Baccini et al. 2008). Heat waves during the early spring can lead to devastation in agriculture systems from subsequent frosts (Gu et al. 2008). Winter heat waves (i.e., thaw events) in northern states have been shown to be disruptive to trees (e.g., Bourque et al. 2005).

Another lesser-examined aspect of heat waves is the difference in heat waves focusing on the opposing and/or combined daily extrema: daytime, nighttime, and simultaneous daytime-nighttime heat waves. These different heat waves hold varying levels of importance to different regions and systems. Periods with both extremely high nighttime and daytime temperatures generally are of more concern for public health officials (Poumadère et al. 2005). Conversely, in the Southwest and southern Great plains, daytime temperature-based heat waves may be more strongly linked to public health impacts (Kalkstein and Davis 1989). In the United States, outside of the Pacific Northwest where Bumbaco et al. (2013) analyzed them, the relationships between these different heat waves are not well understood. The Chen and Li (2017) examination of heat wave types in China demonstrated spatiotemporal changes in the various heat wave types. Previous U.S. studies that have examined differences in which daily extremes were elevated (Oswald and Rood 2014; Smith et al. 2013; Chen and Li 2017; Bumbaco et al. 2013) demonstrated disparity in both mean characteristics and trends.

In this study, a long-term homogenized dataset with a daily time step was leveraged to demonstrate the changes in the spatiotemporal prevalence of heat waves. Changes since 1948 were examined, but the focus was on changes since 1978. This study sought to answer three overarching questions about heat waves:

1) How has the prevalence of heat waves changed through time?

2) Was there a substantial sensitivity in that change to the climate base period methodology?

3) Finally, what were the relationships between different types of heat waves and the relationships with their corresponding statistical moments?

Explicit examination of the driving mechanisms will be the focus of subsequent studies.

\section{Materials and methods}

\section{a. Datasets}

The climatological data used in this study were from the Topography Weather (TopoWx, version 2015.1) dataset (Oyler et al. 2015a). TopoWx was spatially and temporally continuous over the continental United States (CONUS) with a daily temporal resolution and a roughly 800-m native spatial resolution. The TopoWx dataset spanned the 1948-2015 period at time of acquisition (June 2016). All dates throughout the year were utilized in this study. TopoWx data undergo quality control and 
consist of only daily maximum and minimum temperatures. The TopoWx dataset has primarily been used in ecological and streamflow studies in topographically complex regions (e.g., Giersch et al. 2015; Kampf and Lefsky 2016). It has also supported regional studies quantifying historical climate changes (e.g., Oyler et al. 2015b; Sepulveda et al. 2015) but has not yet been used to examine national-scale changes in heat waves.

This study chose TopoWx because it provides daily, homogenized data over a long period of time. To date, no formally homogenized dataset has been employed to examine the changes in heat waves in the United States. Since homogenization removes nonclimatic changes in observational records, it is an essential step in estimating trends. TopoWx is the only homogenized dataset in the peer-reviewed literature covering the United States with daily time steps. TopoWx employs a widely used and accepted homogenization method (Menne and Williams 2009) called the "pairwise homogenization" method. This corrects a wide range of issues including urbanization, time of observation bias, and instrumentation change. To create a truly homogeneous gridded dataset, the stations used (to create the grids) do not vary over the temporal domain of the dataset. Because of its homogeneity TopoWx is preferable for the assessment of changes over time to other popular gridded daily climate datasets, such as the updated Maurer dataset (Livneh et al. 2013), the PRISM "AN81D" dataset (Daly et al. 2008; PRISM Climate Group 2016), and Daymet datasets (Thornton et al. 1997, 2017). Coincidentally, the spatial resolution of TopoWx is also very fine-more so than any other known climate product spanning the United States. Such spatial resolution was achieved by leveraging spatial covariates, including monthly climatologies of satellite-observed daytime and nighttime land skin temperatures that were shown to improve gridded interpolations of near-surface air temperatures (particularly daily minimum temperatures; Oyler et al. 2016). The underlying station observations originate from the Global Historical Climatology Network-Daily (Menne et al. 2012), the Remote Access Weather Station (RAWS) network (Zachariassen et al. 2003), and the Snowpack Telemetry (SNOTEL) network (see https://www.wcc.nrcs.usda.gov/climate/index.html).

Usage of gridded data products was required because of their spatial continuity. Spatial continuity was critical to this study because it sought to synergistically assess the changes in the spatial and temporal aspects of heat waves. Since spatial analyses of heat waves are sorely lacking in the literature, they constitute a major contribution to the understanding of heat waves. It is acknowledged that gridded products do not represent temperature extremes as well as individual station records can because of spatial smoothing. This study's utilization of percentiles in diagnosing heat waves, instead of absolute values, may lessen this limitation's impact. Moreover, this study only examines regionalscale features.

We also acknowledge that limitations of the TopoWx dataset exist. For instance, the homogenization algorithm detects and corrects for changes only in the first statistical moment but not the higher moments. We also concede that in order to maintain a consistent set of stations through time, the infilling routine is heavily utilized in the TopoWx dataset. For instance, the many stations that do not span the 1948-2015 period of the dataset are extended to span it using the infilling method.

The climate data were aggregated from roughly $800 \mathrm{~m}$ to $0.25^{\circ}$ latitude and longitude. This was done because of computational limitations. This aggregation was a simple mean of the gridcell values within the new gridcell domain. Roughly 900 grid cells of high-resolution data go into the mean calculation of each resulting grid cell. This aggregation resulted in a total of 12991 grid cells across the CONUS.

While TopoWx is the only peer-reviewed homogenized climate dataset with daily time steps that covers the United States, another homogenized dataset, the Berkeley Earth Surface Temperature (BEST) dataset (Rohde et al. 2013a), does have an experimental version with daily time steps on $1^{\circ}$ latitude grids (from http:// berkeleyearth.org/data/). The BEST dataset is homogenized in a profoundly different way than the TopoWx dataset is (Rohde et al. 2013b). Analysis of the BEST dataset was not a focus of this study but was rather utilized to provide an estimate of the sensitivity (or lack thereof) of our results to the dataset. Additionally, there exists an ungridded version of the TopoWx dataset. This version of the dataset was utilized to examine the sensitivity of the results to gridding, which naturally suppresses extreme values in records.

To put trends of the heat wave percentage (HW\%) metric into the context of more traditional climate measures, the daily maximum and minimum temperatures from the TopoWx dataset, as well as the diurnal temperature range, were used. The latter was taken as the raw difference of the daily maximum and minimum temperatures. Each year both the mean and variance of the daily maximum and minimum temperatures, as well as the diurnal temperature range, were calculated.

\section{b. Data processing}

This study identified heat waves based on the exceedance of percentile thresholds of air temperatures. Heat index values were not used for two reasons: 1) a desire to focus on the physical changes of the air temperatures 
within the climate system and 2) avoidance of adding uncertainty from atmospheric moisture records. Absolute values were not opted for as thresholds because they are only regionally, and seasonally, applicable.

Percentiles of air temperatures were estimated empirically by calculating the percentage of a sample of temperatures corresponding to that calendar date that was equal to and/or cooler than any given date's temperature. These climate base samples consisted of the observed temperatures at that grid cell within a 9-day calendar window (centered on any given calendar date) during a $30-y r$ period. Therefore, climate base samples consisted of $270(9 \times 30)$ values.

Three types of heat waves were separately quantified and assessed in this study: daily maximum-based waves (Tmax), daily minimum-based waves (Tmin), and both/ simultaneous daily maximum and minimum-based waves (Tmnx). For each type of heat wave two consecutive dates over the 92.5 percent level were required. For Tmax- and Tmin-type waves, the opposing daily extreme temperature was required to exceed the 50 percent level. For Tmnx-type waves, both daily extremes were required to exceed the 92.5 percent level. The 92.5 percent level was opted for because higher percentiles resulted in distributions prone to sampling errors (not shown) and lower threshold samples were less representative of the upper tail of the temperature distribution (Zhang et al. 2012). A longer-duration requirement was not opted for because the resulting reduction in sample size was prone to sampling errors.

To quantify the changes in extreme heat over the 1948-2015 period, HW\% was calculated each year. This metric was taken as the percent of calendar dates and grid cells that experienced a heat wave for any given year. This was then calculated over the entire year, during the summer, and for each month. Notably, it quantifies the portion of dates and grid cells experiencing a heat wave each year and does not measure heat wave intensity, persistence, duration, or spatial extent. It is an admittedly simplistic measure, but the disparities in the temporal changes between different heat wave characteristics can also be trivial (e.g., Oswald and Rood 2014).

\section{c. Analysis methodology}

The analysis began with a cursory evaluation of heat waves as they are defined herein: percent of the dates heat waves were present, their typical spatial coverage of the United States, and the coverage during very hot episodes. Time series of the national HW\% for all three heat wave types were examined. Climatological normals were examined for various time periods and each month. Time series of the national mean and variance of the daily minimum and maximum temperatures were also examined for relationships with the HW\%.
Linear decadal trends in $\mathrm{HW} \%$ were estimated over the 1978-2015 period. This period was chosen because 1) 1978 is the first year of the trailing base period percentiles; 2) preliminary analysis indicated that changes in the HW\% were roughly linear and positive whereas before this period they were decreasing or static in time; and 3) as explained in Zhang et al. (2005), there is a theoretical discontinuity between the last year of the base period (1977) and the first year of the out-of-base period (1978). However, preliminary examination of this impact on various 1948-2015 time series suggested the impacts were insignificant. Linear trends were calculated for the entire calendar year, only during the summer months (June-August), and for individual months. The latter were examined in order to understand the seasonality of heat wave trends.

The trends were estimated using the Sen slope estimation method within the Mann-Kendall test (Mann 1945; Kendall 1975), which is commonly used to estimate trends of extremes because it handles nonparametric distributions well. Simultaneously, the Kendall's tau test for the significance with $95 \%$ confidence ( 0.05 significance level) was calculated to objectively diagnose significance, albeit samples based on the aforementioned heat wave requirements (e.g., related to thresholds and duration) did not have overly nonnormal distributions (not shown).

The statistical relationships between Tmin, Tmax, and Tmnx heat waves were examined in several different ways. Pearson correlation coefficients were calculated between the nationwide HW\% of different heat wave types' time series. The spatial overlap of Tmin and Tmax heat waves was explicitly examined by calculating the portion (spatial percentage) of each date's Tmin/Tmax heat waves that also qualified as Tmnx. This percentage is herein referred to as the "overlap percentage." The median overlap percentage was calculated every year and subsequently examined for changes over the 1948-2015 period. Additionally, on all dates with nonzero heat wave coverage of the United States, the correlation between Tmin and Tmax heat wave spatial patterns was calculated. The median correlation coefficient was then calculated every year and examined for changes in time. Last, at each grid cell the percentages of the Tmin and Tmax dates during the 1948-2015 period that were Tmnx were also calculated. This quantity is herein referred to as the "overlap frequency" of a location. The similarity of the overlap frequency spatial pattern with the diurnal temperature range climate normals was also examined.

While not a focus of this study, the sensitivity of the HW\% trends and time series to a wide range of factors were examined. Heat waves were diagnosed with an alternative definition: two consecutive dates with standardized anomalies of 1.5 or greater and the 
opposing/simultaneous daily extreme being greater than the climate base sample mean. Another test of the sensitivity was by marginally altering the time period the linear trends were calculated over (1978-2015). In addition to the Mann-Kendall method, trends were also calculated using an ordinary least squares regression method. To test the sensitivity of the results the trends were calculated with the BEST dataset as well as the ungridded version of the TopoWx dataset.

Sensitivity of the HW\% trends to the climate base time period was also examined. The analysis was mostly undertaken on what referred to as a "fixed" climate base period, which encompassed the first 30 years of the TopoWx dataset (1948-77). A second type of climate base period was also utilized: a "trailing" base period, which comprised the 30 years preceding any given year. Therefore, the earliest potential date of percentiles based on a trailing base period was in 1978 (i.e., just after the first 30 years of the dataset). This is reminiscent of the optimal climate normals used at the NWS's Climate Prediction Center (Huang et al. 1996), which are calculated from a 10-yr trailing climate base period, and are a better predictor of the next year than climate normals using the traditional (fixed) climate base period.

\section{Results}

The percent of the year-round dates over the entire 1948-2015 period that had nonzero heat wave spatial coverage (nationally) was $91 \%$ for Tmin-type heat waves, $89 \%$ for Tmax waves, and $70 \%$ for Tmnx waves. The median coverage of the United States experiencing a heat wave on any given date was $3.2 \%$ for Tmin-type heat waves, $3.1 \%$ for Tmax waves, and $0.4 \%$ for Tmnx waves. The 90th percentile of that coverage was $18 \%$ for Tmin-type heat waves, $19 \%$ for Tmax waves, and $8 \%$ for Tmnx waves. The maximum HW\% on a single date was $82 \%$ for Tmin-type heat waves (2 January 1997), 63\% for Tmnx waves (same date), and $73 \%$ for Tmax waves (30 October 1950). During the peak of the notorious 1995 heat wave that hit Chicago (i.e., 13 July), 20\% of the United States was covered in a Tmin-type heat wave, $14 \%$ was covered in a Tmnx wave, and $24 \%$ was covered in a Tmax wave.

The national climatological normals of the year-round HW\% during the 1948-77 climate base period were 4.8\% (18 days) for Tmin heat waves, 5.6\% (21 days) for Tmax waves, and $1.9 \%$ (7 days) for Tmnx waves (Table 1 ). During a brief period of general heat wave inactivity and stable statistics (1964-75), the mean values were slightly less, at $4.6 \%$ (17 days) for Tmin heat waves, $4.8 \%$ (17 days) for Tmax waves, and $1.6 \%$ (6 days) for Tmnx waves. However, by the most recent 30 -yr period the same climatological normals had increased to $8.5 \%$ (31 days) for
TABLE 1. Mean year-round and monthly Tmin, Tmnx, and Tmax HW\% values during three periods. Values listed first correspond to the 1948-77 period, those listed second correspond to the 1964-75 period, and those listed third correspond to the 1986-2015 period.

\begin{tabular}{lccc}
\hline \hline & Tmin & Tmnx & Tmax \\
\hline Year-round & $4.8,4.6,8.5$ & $1.9,1.6,3.6$ & $5.6,4.8,8.5$ \\
Dec & $5.0,5.2,6.5$ & $1.9,1.9,2.6$ & $5.5,5.0,7.1$ \\
Jan & $5.3,4.7,6.8$ & $2.3,1.8,3.0$ & $6.0,4.9,8.3$ \\
Feb & $5.2,5.4,8.0$ & $2.2,2.2 .3 .7$ & $5.9,5.9,9.6$ \\
Mar & $4.9,4.5,8.0$ & $1.9,1.6,3.8$ & $5.7,5.0,9.6$ \\
Apr & $4.9,4.8,9.0$ & $1.9,1.8,4.3$ & $5.7,5.4,9.7$ \\
May & $4.9,3.8,8.7$ & $2.0,1.3,3.9$ & $5.7,4.3,8.5$ \\
Jun & $4.9,4.1,10.3$ & $2.0,1.5,4.5$ & $5.7,4.8,9.3$ \\
Jul & $4.7,4.3,11.0$ & $1.9,1.6,4.6$ & $5.6,4.8,9.3$ \\
Aug & $4.6,4.4,10.8$ & $1.7,1.5,4.2$ & $5.5,4.3,9.0$ \\
Sep & $4.5,4.1,8.8$ & $1.5,1.2,3.1$ & $5.5,3.9,7.4$ \\
Oct & $4.6,4.3,7.0$ & $1.5,1.1,2.4$ & $5.4,3.9,6.9$ \\
Nov & $4.8,4.7,6.4$ & $1.7,1.5,2.4$ & $5.5,4.6,6.7$ \\
\hline
\end{tabular}

both Tmin- and Tmax-type heat waves and to $3.6 \%$ (13 days) in the Tmnx waves. Monthly climatological normals indicated modest variability throughout the year (Table 1). Notably, in the earlier 30-yr period, winter had larger Tmin HW\% values, but in the later period, summer had the largest HW\% values. That seasonal cycle of HW\% climate normals was less conspicuous for the Tmax HW\%, but month-to-month variability still existed.

Time series spanning the study period of the national year-round HW\% (Fig. 1a) indicated the background level mildly decreased from 1948 through the mid-1960s and was then followed by a period of general inactivity until the mid- to late 1970s. A continual and substantial increase was evident after that period until 2015. The HW\% in these time series was calculated using percentiles calculated against the fixed climate base period (i.e., always 1948-77). Sensitivity to season and heat wave type existed and included the decreases in year-round Tmax HW\% in the earlier part of the time series being more conspicuous than they were for the Tmin HW\%. Increases in HW\% after the stagnation in the early 1970s were similar for Tmax and Tmin on a year-round basis, but during the summer months Tmin HW\% increased more than Tmax HW\% (Fig. 1b). That difference in increase since 1978 was statistically significant at the $95 \%$ confidence level (not shown). During the summer months, the HW\% increase for all heat wave types was larger than in other seasons (not shown) and year-round.

These temporal changes in national $\mathrm{HW} \%$ were similar to those in the national daily maximum and minimum temperature mean values (Fig. 2), including almost every notable feature. Correlation coefficients between the Tmin (Tmax) HW\% time series and mean Tmin (Tmax) temperatures were strongly positive (e.g., depending on seasonal focus, $0.89-0.92$ in Tmin and 

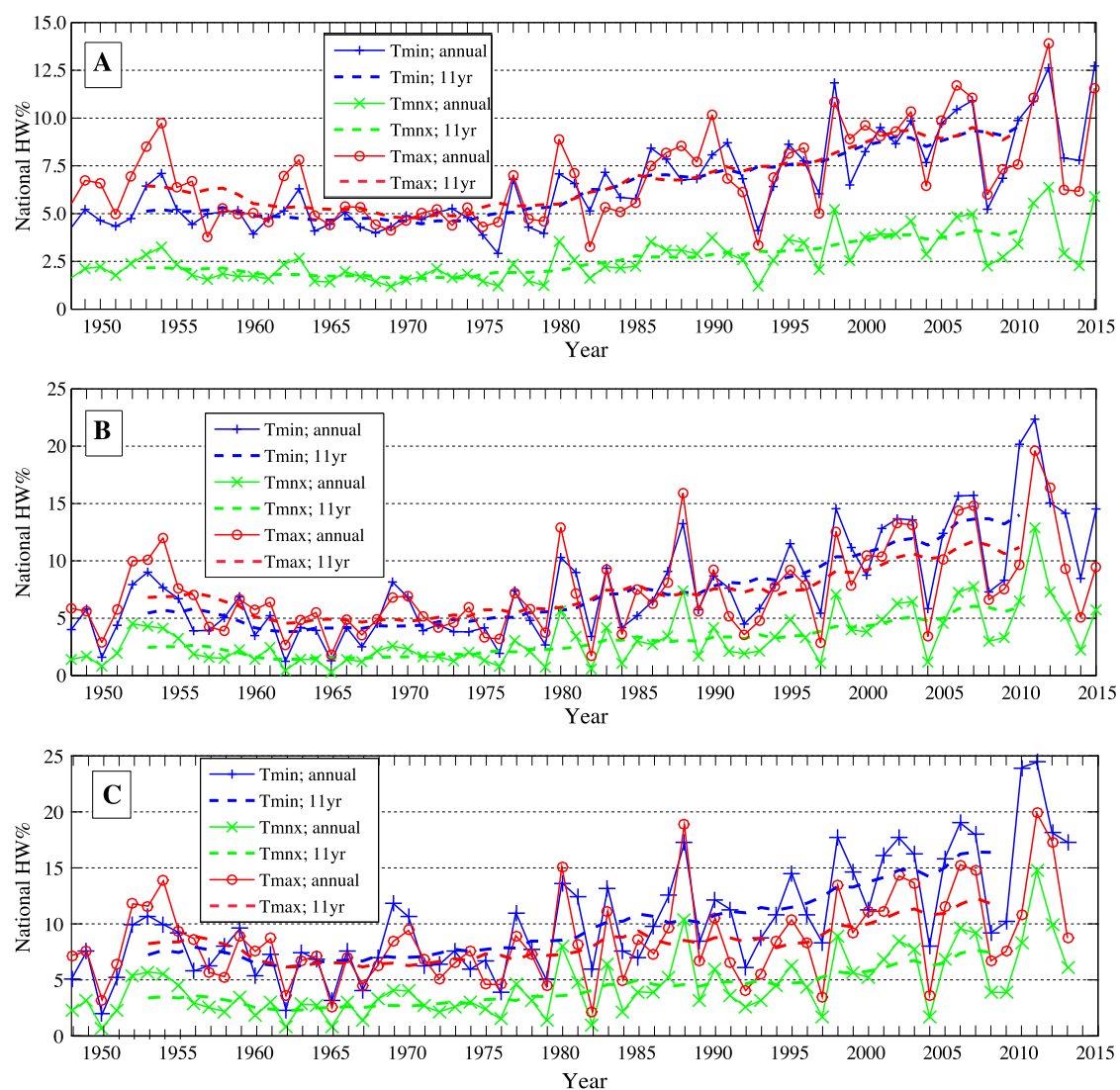

FIG. 1. Time series of nationwide HW\% values for three types of heat waves. Annual values (solid lines with markers) and 11-yr running means (dotted lines, no markers) are both provided for (a) year-round HW\%, (b) summertime HW\%, and (c) summertime HW\% in the BEST dataset.

0.86-0.89 in Tmax). Conversely, similar comparisons with the national daily maximum and minimum temperature variance (not shown) values showed little to no relationship, and correlation coefficients calculated were weak and even negative (e.g., from -0.31 to +0.13 in Tmin and from -0.24 to +0.24 in Tmax).

As compared with the 1948-2015 period, changes since 1978 were roughly linear (Fig. 1). All linear trends of year-round national HW\% during the 1978-2015 period were positive. All three types of heat waves displayed national trends in year-round $\mathrm{HW} \%$ that were statistically significant. In an absolute sense the magnitudes of the national trends were strongest in Tmin HW\% (Table 2), and Tmax trends were very similar (1.38 and 1.31 decade $^{-1}$, respectively). Relative to the climatological normals, however, the Tmnx HW\% increased the most (a $42 \%$ increase per decade as compared with $27 \%-30 \%$ ).

Spatially, positive HW\% linear trends (Table 3) dominated the CONUS. There were no grid cells with significant negative trends in year-round $\mathrm{HW} \%$. The percent of cells with negative trends was largest in Tmax heat waves $(4 \%-6 \%)$. The percent of exactly zero trends was largest in the Tmnx heat waves, particularly in the summer months $(64 \%$ vs $9 \%)$. When trends were determined via ordinary least squares methodology, exactly zero trends were mostly replaced with small positive trends (not shown). Of the positive trends, Tmin had both the largest percentage of positive trends $(89 \%-$ $98 \%$ ) and was the only heat wave type to have a ratio of significant-to-insignificant trends consistently over unity. Conversely, Tmax consistently had the significantto-insignificant ratios under unity.

The spatial patterns of year-round HW\% linear trends (Fig. 3) indicated that, while variability associated with trends of different heat waves types existed, the strongest signal for positive trends focused in a region spanning most of the northern Intermountain West, northern Rockies, central Rockies, southern Rockies, California, Southwest, and southern "High Plains" regions. Less prominent positive trends were located in parts of Florida, the mid-Atlantic, the Great Lakes, northern portions of the upper Mississippi Valley, southern parts of the southern Great plains, and the lower Mississippi Valley. An area of decreasing and/or insignificant trends focused on 

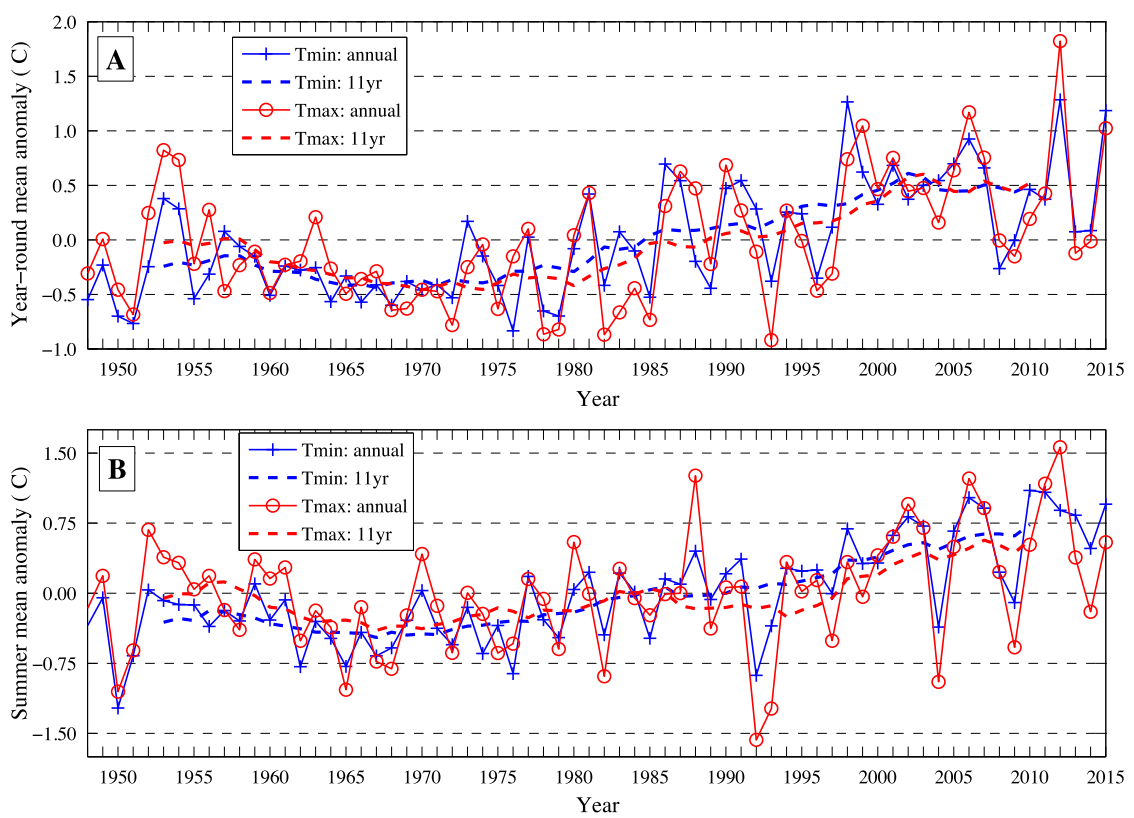

FIG. 2. Time series of nationwide anomaly values for both daily maximum and minimum temperatures. Annual values (solid lines with markers) and 11-yr running means (dotted lines, no markers) are both provided for (a) year-round and (b) summertime. Year-round mean values were $17.5^{\circ}$ and $4.3^{\circ} \mathrm{C}$ for daily maximum and minimum temperatures, respectively. Summer mean values were $28.7^{\circ}$ and $14.4^{\circ} \mathrm{C}$ for daily maximum and minimum temperatures, respectively.

the northern Great plains and extended southeast into the central Great plains, middle Mississippi Valley, and the Ohio and Tennessee Valleys. For Tmnx and Tmax HW types, this weakness in the trends of $\mathrm{HW} \%$ included some parts of the southeastern United States. These general spatial patterns were well supported by maps of trends calculated via ordinary least squares regression (e.g., maps not shown but correlation coefficients are 0.96 and 0.94 for Tmin and Tmax HW\%, respectively).
The national HW\% linear trends displayed the largest magnitudes in the summer months (Table 2). This was most evident for the Tmin heat waves, where the magnitudes were nearly double that of the annual trends. There was no season that displayed exceptionally weak trends, but March and January both exhibited weak trends for most heat wave types. Each heat wave type had exactly 6 months with statistically significant trends. The summer months plus September

TABLE 2. Nationwide linear decadal trends in HW\% during the 1978-2015 period. Values in parentheses are normalized by the mean 1964-75 period values. Statistical significance is indicated by boldface font.

\begin{tabular}{|c|c|c|c|c|c|c|}
\hline & \multicolumn{3}{|c|}{ 1948-77 climate base } & \multicolumn{3}{|c|}{ Trailing climate base } \\
\hline & Tmin & Tmnx & Tmax & Tmin & Tmnx & Tmax \\
\hline Year-round & $\mathbf{1 . 3 8}(0.30)$ & $\mathbf{0 . 6 9}(0.42)$ & $\mathbf{1 . 3 1}(0.27)$ & $0.36(0.08)$ & $0.17(0.10)$ & $0.24(0.05)$ \\
\hline Dec & $0.72(0.14)$ & $0.44(0.23)$ & $0.81(0.16)$ & $0.44(0.09)$ & $0.22(0.11)$ & $0.24(0.05)$ \\
\hline Jan & $0.15(0.03)$ & $0.34(0.19)$ & $1.11(0.23)$ & $-0.20(-0.04)$ & $0.08(0.41)$ & $0.21(0.04)$ \\
\hline Feb & $0.55(0.10)$ & $\mathbf{0 . 6 0}(0.27)$ & $\mathbf{1 . 5 1}(0.26)$ & $-0.04(-0.01)$ & $0.17(0.08)$ & $0.34(0.06)$ \\
\hline Mar & $0.03(0.01)$ & $0.25(0.16)$ & $0.74(0.15)$ & $-0.57(-0.13)$ & $-0.18(-0.11)$ & $-0.27(-0.05)$ \\
\hline Apr & $0.78(0.16)$ & $0.56(0.31)$ & $\mathbf{1 . 3 3}(0.24)$ & $-0.17(-0.04)$ & $-0.07(-0.04)$ & $0.22(0.04)$ \\
\hline May & $\mathbf{1 . 0 2}(0.27)$ & $0.54(0.42)$ & $1.00(0.23)$ & $0.04(0.01)$ & $0.05(0.04)$ & $0.17(0.04)$ \\
\hline Jun & $\mathbf{2 . 0 8}(0.51)$ & $\mathbf{0 . 8 8}(0.58)$ & $\mathbf{1 . 3 1}(0.27)$ & $0.48(0.11)$ & $0.17(0.11)$ & $0.23(0.05)$ \\
\hline Jul & $\mathbf{2 . 6 7}(0.62)$ & $1.08(0.67)$ & $\mathbf{1 . 6 0}(0.33)$ & $0.69(0.16)$ & $0.31(0.19)$ & $0.42(0.09)$ \\
\hline Aug & $2.87(0.65)$ & $\mathbf{0 . 9 9}(0.66)$ & $\mathbf{1 . 2 7}(0.29)$ & $\mathbf{0 . 8 4}(0.19)$ & $0.19(0.13)$ & $0.15(0.03)$ \\
\hline Sep & $\mathbf{1 . 7 6}(0.43)$ & $\mathbf{0 . 5 3}(0.46)$ & $\mathbf{0 . 8 8}(0.22)$ & $0.55(0.13)$ & $0.09(0.08)$ & $0.13(0.03)$ \\
\hline Oct & $\mathbf{0 . 9 7}(0.23)$ & $\mathbf{0 . 4 6}(0.42)$ & $0.89(0.23)$ & $0.38(0.09)$ & $0.11(0.10)$ & $0.30(0.08)$ \\
\hline Nov & $0.83(0.18)$ & $0.43(0.29)$ & $0.84(0.18)$ & $0.53(0.11)$ & $0.22(0.15)$ & $0.38(0.08)$ \\
\hline
\end{tabular}


TABLE 3. Percentage of the CONUS with various types of linear trends. The first value represents the Tmin heat wave type, the second represents the Tmnx type, and the third represents the Tmax type. For clarity, extra precision is given to values under $1 \%$.

\begin{tabular}{lcc}
\hline \hline & Year-round & Summertime \\
\hline Positive significant & $53,38,42$ & $55,26,27$ \\
Positive insignificant & $45,51,49$ & $34,10,30$ \\
No trend & $1,9,4$ & $11,64,39$ \\
Negative insignificant & $1,2,6$ & $0.2,0.0,3$ \\
Negative significant & $0.0,0.0,0.0$ & $0.0,0.0,0.7$ \\
\hline
\end{tabular}

(i.e., June-September) were consistently significant across the various heat wave types.

Despite having larger national (positive) HW\% trends in the summertime, the spatial coverage of positive trends over the United States was less dominated than they were in year-round trends (Table 3). This was more than offset by the magnitude increases. Most notably, the decrease in spatial coverage was due to an increase in the percent of exactly zero trends (Table 3). This increase (in zeromagnitude trends) may have been a response within the trend estimation method to a relatively large amount of variability relative to the change in the background mean. Summertime Tmin HW\% had roughly double the coverage of significant positive trends as the second highest heat wave type (55\% versus $27 \%$ for Tmax). Tmax heat waves had the highest percent of negative trends (3.7\%), and the summertime heat waves even had grid cells with significant negative trends $(0.7 \%)$.

The spatial patterns in linear trends of HW\% during the summertime (Fig. 4) displayed patterns similar to the year-round $\mathrm{HW} \%$ trends. The region of positive trends in the western United States again displayed the strongest trends, and the northern Great plains displayed decreasing trends or no trends. The range in the trends was substantially larger in the summertime than it was in the year-round trends. The trends in the Tmnx events displayed an exceptionally large portion of the United States with no trend at all. This area of zero-value trends spanned from the northern to southern Great plains and almost all areas east, outside of parts of Florida, the Carolinas, and the middle Mississippi Valley. Corresponding maps of trends calculated via ordinary least squares regression confirmed these spatial patterns (e.g., correlation coefficients of 0.95 and 0.72 , for Tmin and Tmax HW\%, respectively) but mostly replaced zero-value trends with very small positive trends. The differences with ordinary least squares regression patterns were greater in the Tmax HW\%.

Spatial patterns of 1978-2015 trends in the mean daily maximum temperatures (Fig. 5) were more similar with those in Tmax HW\% (e.g., correlation coefficients $0.70-0.79)$ than patterns in the mean daily minimum temperatures were similar to Tmin HW\% (correlation

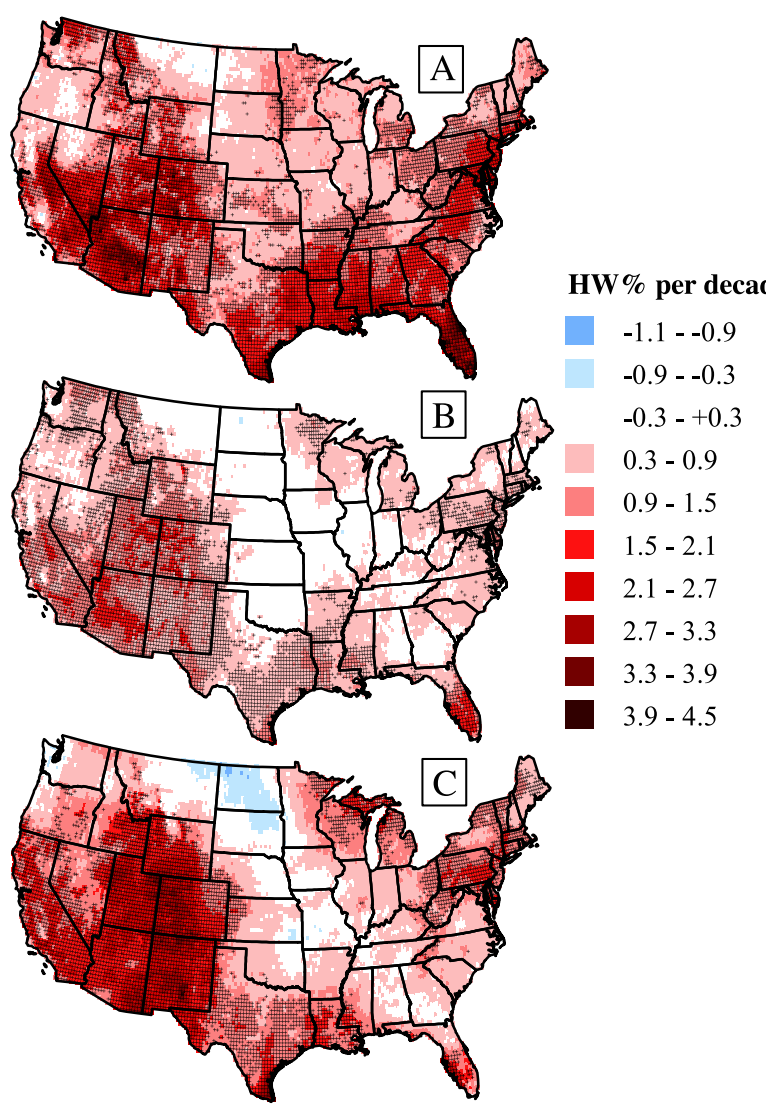

FIG. 3. Maps of the sign, magnitude, and statistical significance of the linear decadal trends in year-round HW\% over the 1978-2015 period. Heat waves of the (a) Tmin, (b) Tmnx, and (c) Tmax types are displayed. Statistical significance is indicated with hatching.

coefficients $0.37-0.39)$. To a lesser extent, the opposite was true for the variance [i.e., more similarity in daily minimum temperatures (correlation coefficients 0.43 $0.64)$ than in the daily maximum temperatures (correlation coefficients $0.30-0.50)$ ]. Overall, the trends in HW\% were substantially closer aligned with trends in the mean (Fig. 5; typical correlation coefficient around 0.55 ) than they were with trends in the variance (not shown, but typical correlation coefficient around 0.35).

The temporal correlation coefficients of the national HW\% over the 1948-2015 period (as seen in Fig. 1), in both the summer and year-round, displayed very strong positive (0.94-0.96) correlations between Tmin-/Tmaxand Tmnx-type heat waves. The correlations between Tmax- and Tmin-type heat waves were weaker but still strongly positive $(\sim 0.87)$. The median overlap percentage in the $1948-2015$ period was roughly $19 \%$ and $26 \%$, respectively, for year-round and summertime heat waves. However, the values of those overlap percentages noticeably changed through time (Fig. 6a). Although there was large year-to-year variability, there also was a mild 


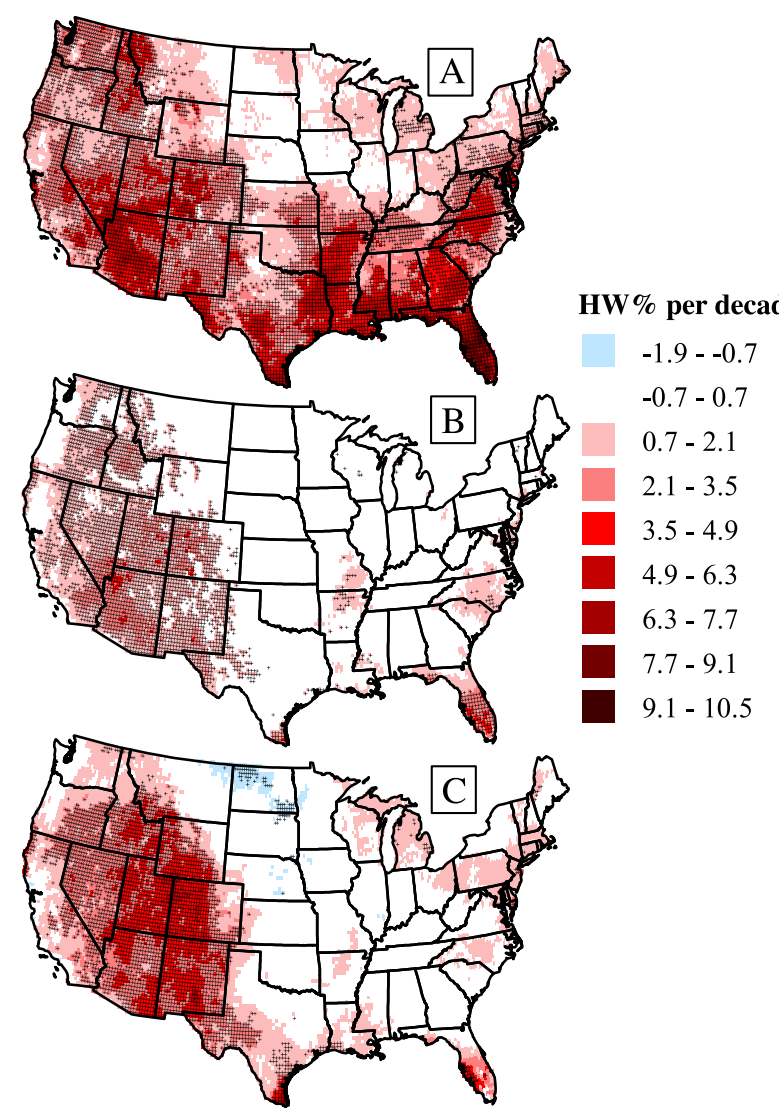

FIG. 4. As in Fig. 3, but for summertime HW\% over the 19782015 period.

decrease in the mean from 1948 until the mid- to late 1960s and then a conspicuous increase through 2015. The recent increase was substantial in the sense that it more than doubled from $\sim 12 \%$ in 1970 to $27 \%$ in 2015 . This same behavior was seen in the percentage of Tmin/Tmax dates that included a nonzero percentage of Tmnx (not shown). Changes over time in the national mean daily diurnal temperature range failed to have a meaningful relationship with the aforementioned changes in overlap percentage (negative correlations anticipated, but correlation coefficients were positive at $0.35-0.36$ ). The mean values of the spatial correlation coefficients calculated between simultaneous daily Tmax and Tmin heat wave patterns across the United States over the 1948-2015 period were weak at 0.22 and 0.28 for year-round and summertime values, respectively. The median correlation coefficient changed through time in a highly similar way to the median spatial overlap percentage (Fig. 6b), albeit to a slightly lesser degree (e.g., the increase from 1970 to 2015 was not quite a doubling).

The overlap frequencies (Fig. 7a), were calculated on samples that usually totaled to about 1100 in size (i.e., dates of Tmin- or Tmax-type heat waves). West of the

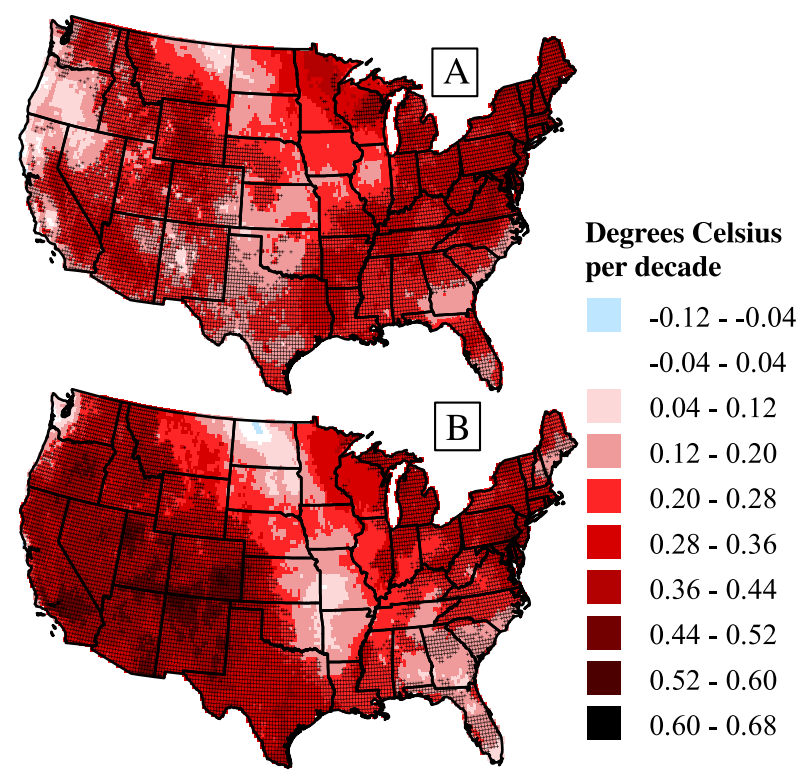

FIG. 5. Maps of the linear decadal trends in year-round mean daily air temperatures. Displayed are trends in both (a) daily minimum temperatures and (b) daily maximum temperatures. Statistical significance is indicated with hatching.

Rockies, the overlap frequencies were usually high. A region of generally low overlap frequencies covered the northern and central Great plains. A region with generally high overlap frequencies extended from the upper and middle Mississippi Valley through parts of the central Great plains and into southern Great plains. Comparisons between overlap frequency and the 1948-2015 period mean diurnal temperature range indicated an overall weak but complex relationship. For instance, while a 0.00 correlation coefficient was calculated nationwide, regions of both positive and negative relationships appeared to exist (Fig. 7b).

In addition to confirming the results with trends calculated with ordinary least squares regression, the results were also reanalyzed with the BEST dataset, with the alternative definition of a heat wave (e.g., standard deviations instead of percentiles), with an ungridded version of the TopoWx dataset (not shown), and over slightly different time periods. While the sensitivity to these aforementioned variables was low, the largest sensitivity was to the time period (i.e., start and end date). For instance, the time series of national HW\% was not conspicuously sensitive to dataset (Fig. 1), albeit the beginning of the increase does start a few years earlier in the BEST dataset. The spatial pattern of summer HW\% trends calculated over the 1978-2013 period, using ordinary least squares regression, on the BEST dataset, and with a heat wave definition based on the standard anomaly (Fig. 8) had a similar spatial pattern to the results of the primary analysis (Fig. 4). 



FIG. 6. Time series of nationwide (a) median percent of overlap between daily simultaneous Tmin/Tmax heat wave patterns and (b) median correlation coefficient between daily simultaneous Tmin/Tmax heat wave patterns. Both annual values and 11-yr running averages are provided for both year-round HW\% and summertime HW\%.

The major sensitivity was to the climate base period. The trends in the national HW\% were substantially smaller when diagnosed against the trailing, as opposed to a fixed, climate base period (Table 2). The trailing base period trends in the year-round HW\% Tmin and Tmax were an order of magnitude less than their (fixed base period) counterparts, albeit the Tmnx reductions were less pronounced. Negative trends even existed for some months and totaled to four in the Tmin-type heat waves, two in the Tmnx waves, and one in the Tmax waves. Negative trends only existed between the months of January and April. Only one instance, Tmin HW\% in August, had statistically significant (positive) trends.

\section{Discussion and conclusions}

This analysis of the changes in the heat wave percentage (HW\%) was the first to utilize a homogenized climate dataset (TopoWx) and was therefore significant to the understanding of the changes in heat waves. 

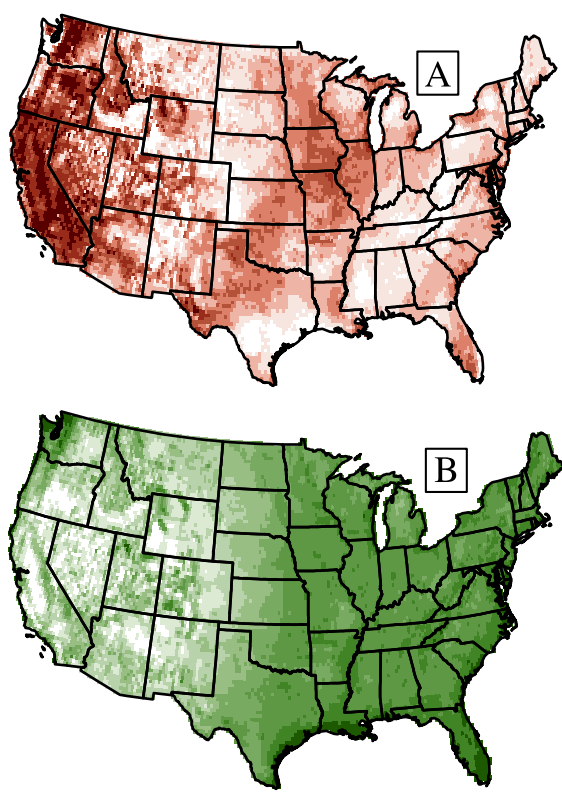

\section{Diurnal range} (degrees Celsius) $7.5-10.7$ $10.7-12.2$ $12.2-13.2$ $13.2-14.5$ $14.5-15.8$ $15.8-17.2$ $17.2-18.8$ $18.8-22.8$

FIG. 7. Maps of the (a) pattern of the percentage of the MaySeptember dates considered either a Tmin or Tmax heat wave during the 1948-2015 period that also qualified as a Tmnx heat wave and (b) mean diurnal temperature range during the MaySeptember months during the 1948-2015 period.

The findings herein confirmed several previous studies' conclusions as well as produced an array of new conclusions. Foremost, it confirmed that heat wave prevalence mildly declined nationally prior to the 1970 s, but since the 1970s a steady and substantial increase occurred. Increases observed in the most recent decade confirm the absence of a warming pause in extreme temperatures, as noted by Seneviratne et al. (2014). Increases in HW\% since the 1970s were clearly seen in the time series of nationwide HW\%, and they mirrored changes in the mean temperatures. Also, the portion of the United States that experienced increases as compared with decreases in HW\% since 1978 was overwhelmingly in favor of the increases; statistically significant negative trends were nearly nonexistent. These conclusions confirm well-established mild decreases (nationally) in nighttime and daytime hot temperatures/heat waves from the late 1940s to the 1970s (e.g., Oswald and Rood 2014; DeGaetano and Allen 2002; Alexander et al. 2006). Similarly, they confirm a previously observed substantial increase since the late 1970s (e.g., Smith et al. 2013; Oswald and Rood 2014; Habeeb et al. 2015). Since this increase was substantially larger than the preceding (e.g., 1948-77) decreases, these results also confirmed increasing trends in heat waves since the mid-twentieth century (e.g., Alexander et al. 2006; Allen and Sheridan 2016). It is thought that the utilization of a reanalysis-based dataset in the Smith et al. (2013) study is the reason the resulting spatial patterns do not agree with one another.
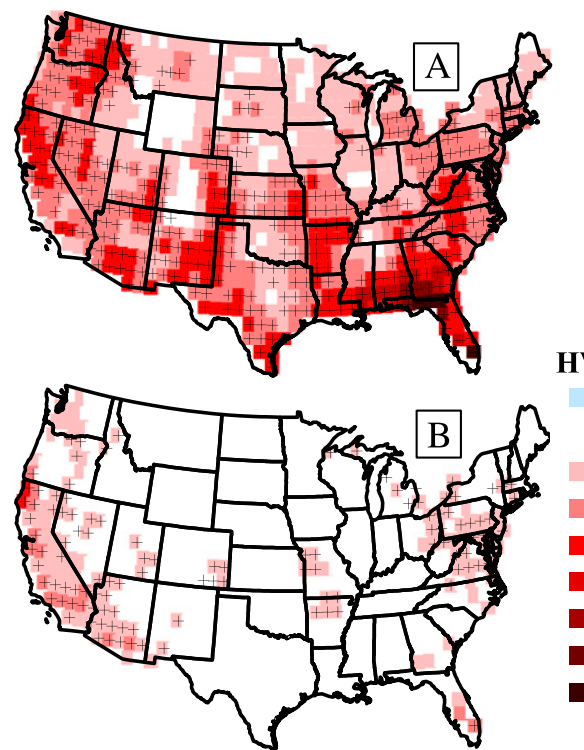

HW\% per decade

$-1.50--0.50$

$-0.50-+0.50$

$0.50-1.50$

$1.50-2.50$

$2.50-3.50$

- $3.50-4.50$

- $4.50-5.50$

$5.50-6.50$

$6.50-8.50$

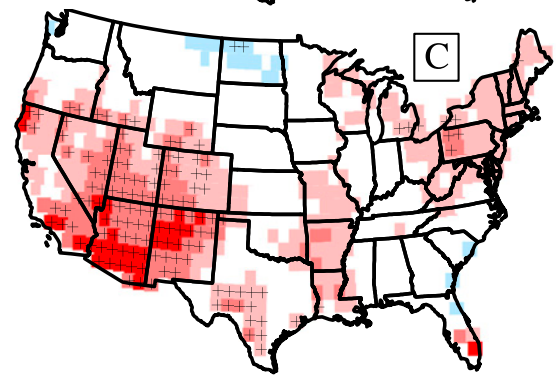

FIG. 8. Maps of the sign, magnitude, and statistical significance of the linear decadal trends in summertime HW\% over the 1978-2013 period. These heat waves were based on standard deviations and calculated from the BEST dataset. Heat waves of the (a) Tmin type, (b) Tmnx type, and (c) Tmax type are displayed. Statistical significance is indicated with hatching.

Examination of the magnitude and spatial coverage of linear trends of the 1978-2015 period in the nationwide HW\% for all three types of heat waves for each month clearly demonstrated that the increase since the late 1970s in the HW\% was greatest in the summer months and least in Tmax-type heat waves. We know of no other studies that have examined the seasonality of heat wave trends. Increases dominated by summer months could be unexpected in the context of greenhouse gas warming; however, the bulk of the temperature increase due to greenhouse gases occurs in the cold tail of the distribution. When linear trends were normalized by climate normals, Tmnx-type heat waves increased the most, but the absolute trends were largest in Tmin-type heat waves. A greater increase in Tmin than Tmax is supported by almost all known studies (Perkins 2015). Results agreed with the Oswald and Rood (2014) analysis, which used a crudely assembled homogenized dataset, that the normalized trends of the Tmnx-type heat waves in the 
United States were the largest of the three types (and Tmin was largest when they are not normalized).

Geographically, the largest increases since the 1970s were found in the western United States (not including the Pacific Northwest or northern Rockies), and the weakest were found in an area that centered on the northern Great plains but extended often through the central Great plains and into the middle Mississippi Valley; sometimes this region extended into the Ohio and Tennessee Valleys and even the southeastern United States. This feature existed in both maps of yearround and summer season trends. Such a feature agrees with a few other studies indicating a warming hole stemming from the northern Great plains (Oswald and Rood 2014; Allen and Sheridan 2016). However, many studies do not confirm such a pattern (Peterson et al. 2013; Alexander et al. 2006; Grotjahn et al. 2016; Meehl et al. 2012; Brown et al. 2008; Donat et al. 2013; Portmann et al. 2009; Frich et al. 2002) and instead depict the warming hole to be in the southeastern United States. These studies all had start dates of 1950, which suggests the warming hole shifted toward the northern Great plains in more recent years. Notably, any period ending in recent years with a start date of 1950 includes nonlinear changes. Studies of trends in extreme heat usually depict a general east-west dipole of trends (Brown et al. 2008; Donat et al. 2013; Portmann et al. 2009; Alexander et al. 2006; Frich et al. 2002), and our results confirm such a pattern exists in the trends of daily maximum-based heat waves. Many studies also indicate a local maximum of increase in the western and southwestern United States for trends of extremes based on the daily minimum temperature (Brown et al. 2008; Portmann et al. 2009; Alexander et al. 2006; Donat et al. 2013). This study confirms such a feature but also suggests a larger region/signal as well as an extension of this feature into both the daily maximum and combined daily maximum and minimum (Tmnx)-based heat wave trends.

This study confirmed that changes in HW\% were very similar to changes in the statistical means of the corresponding daily extreme temperature (e.g., Hansen et al. 2012; McKinnon et al. 2016; Donat and Alexander 2012). This was evidenced by comparisons of similarity with both the mean and variance of daily temperature extremes and the national HW\% through time, as well as through comparisons of spatial maps of increase. More similarity with HW\% existed with the statistical mean than the variance. There were stronger relationships between HW\% and the statistical mean during the daytime and between $\mathrm{HW} \%$ and the statistical variance during the nighttime.

The results of this analysis were not sensitive to a wide range of factors, for instance, dataset or trend estimation methodology. However, the increases since the 1970s were only significant if heat waves were diagnosed relative to a fixed climate base period. This was demonstrated in comparisons of the 1978-2015 linear trends of heat waves based on percentiles relative to both fixed climate bases and trailing climate bases. We are unaware of any previous examination of the sensitivity to climate base methodology. We recognize this finding may not be relevant to understanding the physical changes of the climate system or with respect to the exceedances of absolute thresholds. However, from an epidemiological standpoint, it may be extremely important. Studies in the epidemiological field are in agreement that the relationship between temperature percentiles using a fixed climate base and health statistics has weakened with time (e.g., Sheridan and Dixon 2017). This supports the idea that the population becomes acclimated to hotter weather over time. Extreme heat with respect to a trailing base period should be evaluated for a relationship to health statistics that does not decline over time.

The likelihood of Tmin and Tmax heat waves intersecting (i.e., Tmnx heat waves) was dynamic through time and space. The temporal pattern on the national level showed a decrease prior to the mid-1960s and a subsequent increase. Chen and $\mathrm{Li}$ (2017) also observed a temporal increase in the probability of Tmin/Tmax overlap since the 1970s in China. The temporal pattern observed in this study was similar to national trends in atmospheric moisture content (Brown and DeGaetano 2013). This could potentially be linked to the relatively larger increases in HW\% of heat wave types with respect to both daily maximum and minimum temperatures (Tmnx). It was, however, not related to temporal patterns of change in the diurnal temperature range. Studies that advance the knowledge of the temporal changes in the relationships between Tmin, Tmax, and Tmnx heat waves in the United States would be beneficial. The likelihood of simultaneous Tmin- and Tmax-type heat waves also demonstrated spatial variability, as seen in maps of the overlap frequency of 1948-2015. These findings echo those of Chen and $\mathrm{Li}$ (2017) that meaningful spatial variability exists in the likelihood for a Tmnx heat wave to be experienced instead of a single extremum (Tmin or Tmax) heat wave. The relationship between overlap frequency and the mean diurnal temperature range was not meaningful. Knowledge concerning the drivers of overlap frequency, related to either weather or surface conditions, should be further investigated.

Acknowledgments. A very special thanks is given to Drs. Kai Zhang, Huug van den Dool, Balachandrudu Narapusetty, and Jared Oyler and the three journal reviewers for valuable manuscript reviews. 


\section{REFERENCES}

Alexander, L. V., and Coauthors, 2006: Global observed changes in daily climate extremes of temperature and precipitation. J. Geophys. Res., 111, D05109, https://doi.org/10.1029/ 2005JD006290.

Allen, M. J., and S. C. Sheridan, 2016: Spatio-temporal changes in heat waves and cold spells: An analysis of 55 U.S. cities. Phys. Geogr., 37, 189-209, https://doi.org/10.1080/02723646.2016.1184078.

Baccini, M., and Coauthors, 2008: Heat effects on mortality in 15 European cities. Epidemiology, 19, 711-719, https://doi.org/ 10.1097/EDE.0b013e318176bfcd.

Bao, J., X. Li, and C. Yu, 2015: The construction and validation of the heat vulnerability index, a review. Int. J. Environ. Res. Public Health, 12, 7220-7234, https://doi.org/10.3390/ ijerph120707220.

Bourque, C. P.-A., R. M. Cox, D. J. Allen, P. A. Arp, and F.-R. Meng, 2005: Spatial extent of winter thaw events in eastern North America: Historical weather records in relation to yellow birch decline. Global Change Biol., 11, 1477-1492, https://doi.org/10.1111/j.1365-2486.2005.00956.x.

Brown, P. J., and A. T. DeGaetano, 2013: Trends in U.S. surface humidity, 1930-2010. J. Appl. Meteor. Climatol., 52, 147-163, https://doi.org/10.1175/JAMC-D-12-035.1.

Brown, S. J., J. Caesar, and C. A. T. Ferro, 2008: Global changes in extreme daily temperature since 1950. J. Geophys. Res., 113, D05115, https://doi.org/10.1029/2006JD008091.

Bumbaco, K. A., K. D. Dello, and N. A. Bond, 2013: History of Pacific Northwest heat waves: Synoptic pattern and trends. J. Appl. Meteor. Climatol., 52, 1618-1631, https://doi.org/ 10.1175/JAMC-D-12-094.1.

Chen, Y., and Y. Li, 2017: An inter-comparison of three heat wave types in China during 1961-2010: Observed basic features and linear trends. Sci. Rep., 7, 45619, https://doi.org/ $10.1038 /$ srep45619.

Cohen, J., and Coauthors, 2014: Recent Arctic amplification and extreme mid-latitude weather. Nat. Geosci., 7, 627-637, https://doi.org/10.1038/ngeo2234.

Daly, C., M. Halbleib, J. I. Smith, W. P. Gibson, M. K. Doggett, G. H. Taylor, J. Curtis, and P. P. Pasteris, 2008: Physiographically sensitive mapping of climatological temperature and precipitation across the conterminous United States. Int. J. Climatol., 28, 2031-2064, https://doi.org/ 10.1002/joc. 1688 .

DeGaetano, A. T., and R. J. Allen, 2002: Trends in twentiethcentury temperature extremes across the United States. J. Climate, 15, 3188-3205, https://doi.org/10.1175/1520-0442 (2002) $015<3188$ :TITCTE $>2.0$. CO;2.

Donat, M. G., and L. V. Alexander, 2012: The shifting probability distribution of global daytime and night-time temperatures. Geophys. Res. Lett., 39, L14707, https://doi.org/10.1029/ 2012 GL052459.

—_, and Coauthors, 2013: Updated analyses of temperature and precipitation extreme indices since the beginning of the twentieth century: The HadEX2 dataset. J. Geophys. Res. Atmos., 118, 2098-2118, https://doi.org/10.1002/jgrd.50150.

Frich, P., L. V. Alexander, P. Della-Marta, B. Gleason, M. Haylock, A. M. G. Klein Tank, and T. Peterson, 2002: Observed coherent changes in climatic extremes during the second half of the twentieth century. Climate Res., 19, 193-212, https://doi.org/10.3354/cr019193.

Giersch, J. J., S. Jordan, G. Luikart, L. A. Jones, F. R. Hauer, and C. C. Mulfeld, 2015: Climate-induced range contraction of a rare alpine aquatic invertebrate. Freshwater Sci., 34, 53-65, https://doi.org/10.1086/679490.

Grotjahn, R., and Coauthors, 2016: North American extreme temperature events and related large scale meteorologic patterns: A review of statistical methods, dynamics, modeling, and trends. Climate Dyn., 46, 1151-1184, https://doi.org/ 10.1007/s00382-015-2638-6.

Gu, L., P. J. Hanson, W. M. Post, D. P. Kaiser, B. Yang, R. Nemani, S. G. Pallardy, and T. Meyers, 2008: The 2007 eastern US spring freeze: Increased cold damage in a warming world? Bioscience, 58, 253-262, https://doi.org/ 10.1641/B580311.

Habeeb, D., J. Vargo, and B. Stone Jr., 2015: Rising heat wave trends in large US cities. Nat. Hazards, 76, 1651-1665, https:// doi.org/10.1007/s11069-014-1563-z.

Hansen, J., M. Sato, and R. Ruedy, 2012: Perception of climate change. Proc. Natl. Acad. Sci. USA, 109, E2415-E2423, https:// doi.org/10.1073/pnas.1205276109.

Howden, S. M., and J. Turnpenny, 1997: Modelling heat stress and water loss of beef cattle in subtropical Queensland under current climates and climate change. Modsim 97, Canberra, Australia, Modelling and Simulation Society of Australia, 1103-1108.

Huang, J., H. M. van den Dool, and A. G. Barnston, 1996: Long-lead seasonal temperature prediction using optimal climate normals. J. Climate, 9, 809-817, https://doi.org/10.1175/1520-0442(1996) 009<0809:LLSTPU > 2.0.CO;2.

Isaac, M., and D. P. van Vuuren, 2009: Modeling global residential sector energy demand for heating and air conditioning in the context of climate change. Energy Policy, 37, 507-521, https:// doi.org/10.1016/j.enpol.2008.09.051.

Kalkstein, L. S., and R. E. Davis, 1989: Weather and human mortality: An evaluation of demographic and interregional responses in the United States. Ann. Assoc. Amer. Geogr., 79, 44-64, https://doi.org/10.1111/j.1467-8306.1989.tb00249.x.

Kampf, S. K., and M. A. Lefsky, 2016: Transition of dominant peak flow source from snowmelt to rainfall along the Colorado Front Range: Historical patterns, trends, and lessons from the 2013 Colorado Front Range floods. Water Resour. Res., 52, 407-422, https://doi.org/10.1002/2015WR017784.

Kendall, M. G., 1975: Rank Correlation Methods. Griffin, 160 pp.

Knappenberger, P. C., P. J. Michaels, and R. E. Davis, 2001: Nature of observed temperature changes across the United States during the 20th century. Climate Res., 17, 45-53, https://doi.org/ 10.3354/cr017045.

Knowlton, K., M. Rotkin-Ellman, G. King, H. G. Margolis, D. Smith, G. Solomon, R. Trent, and P. English, 2009: The 2006 California heat wave: Impacts on hospitalizations and emergency department visits. Environ. Health Perspect., 117, 61-67, https://doi.org/10.1289/ehp.11594.

Livneh, B., E. A. Rosenberg, C. Lin, B. Nijssen, V. Mishra, K. M. Andreadis, E. P. Maurer, and D. P. Lettenmaier, 2013: A longterm hydrological based dataset of land surface fluxes and states for the conterminous United States: Update and extensions. J. Climate, 26, 9384-9392, https://doi.org/10.1175/ JCLI-D-12-00508.1.

Lowe, D., K. L. Ebi, and B. Forsbeg, 2011: Heat wave early warning systems and adaptation advice to reduce human health consequences of heat waves. Int. J. Environ. Public Health, 8, 4623-4648, https://doi.org/10.3390/ijerph8124623.

Mader, T. L., 2003: Environmental stress in confined beef cattle. J. Anim. Sci., 81 (Suppl.), E110-E119, https://doi.org/10.2527/ 2003.8114_suppl_2E110x. 
Mann, H. B., 1945: Nonparametric tests against trend. Econometrica, 13, 245-259, https://doi.org/10.2307/1907187.

McGregor, G. R., M. Felling, T. Wolf, and S. Gosling, 2007: The social impact of heat waves. Environmental Agency Rep., 40 pp.

McKinnon, K. A., A. Rhines, M. P. Tingley, and P. Huybers, 2016: The changing shape of Northern Hemisphere summer temperature distributions. J. Geophys. Res. Atmos., 121, 88498868, https://doi.org/10.1002/2016JD025292.

Meehl, G. A., C. Tebaldi, G. Walton, D. Easterling, and L. McDaniel, 2009: Relative increase of record high maximum temperatures compared to record low minimum temperatures in the U.S. Geophys. Res. Lett., 36, L23701, https://doi.org/ 10.1029/2009GL040736.

_ J. M. Arblaster, and G. Branstator, 2012: Mechanisms contributing to the warming hole and the consequent U.S. east-west differential of heat extremes. J. Climate, 25, 6394-6408, https:// doi.org/10.1175/JCLI-D-11-00655.1.

Menne, M. J., and C. N. Williams Jr., 2009: Homogenization of temperature series via pairwise comparisons. J. Climate, 22, 1700-1717, https://doi.org/10.1175/2008JCLI2263.1.

— _ _ , and R. S. Vose, 2009: The United States Historical Climatology Network monthly temperature data, version 2. Bull. Amer. Meteor. Soc., 90, 993-1008, https://doi.org/ 10.1175/2008BAMS2613.1.

—, I. Durre, R. S. Vose, B. E. Gleason, and T. G. Houston, 2012: An overview of the Global Historical Climatology NetworkDaily database. J. Atmos. Oceanic Technol., 29, 897-910, https://doi.org/10.1175/JTECH-D-11-00103.1.

Oswald, E. M., and R. B. Rood, 2014: A trend analysis of the 19302010 extreme heat events in the continental United States. J. Appl. Meteor. Climatol., 53, 565-582, https://doi.org/10.1175/ JAMC-D-13-071.1.

Oyler, J. W., A. Ballantyne, K. Jencso, M. Sweet, and S. W. Running, 2015a: Creating a topoclimatic daily air temperature dataset for the conterminous United States using homogenized station data and remotely sensed land skin temperature. Int. J. Climatol., 35, 2258-2279, https://doi.org/10.1002/joc.4127.

—-, S. Z. Dobrowski, A. Ballantyne, A. E. Klene, and S. W. Running, 2015b: Artificial amplification of warming trends across the mountains of the western United States. Geophys. Res. Lett., 42, 153-161, https://doi.org/10.1002/ 2014 GL062803.

_ — _ Z Z. A. Holden, and S. W. Running, 2016: Remotely sensed land skin temperature as a spatial predictor of air temperature across the conterminous United States. J. Appl. Meteor. Climatol., 55, 1441-1457, https://doi.org/10.1175/ JAMC-D-15-0276.1.

Pan, Z., R. W. Arritt, E. S. Takle, W. J. Gutowski Jr., C. J. Anderson, and M. Segal, 2004: Altered hydrologic feedback in a warming climate introduces a "warming hole." Geophys. Res. Lett., 31, L17109, https://doi.org/10.1029/ 2004 GL020528.

Perkins, S. E., 2015: A review on the scientific understanding of heatwaves-Their measurement, driving mechanisms, and changes at the global scale. Atmos. Res., 164-165, 242-267, https://doi.org/10.1016/j.atmosres.2015.05.014.

Peterson, T. C., and Coauthors, 2013: Monitoring and understanding changes in heat waves, cold waves, floods, and droughts in the United States: State of knowledge. Bull. Amer. Meteor. Soc., 94, 821-834, https://doi.org/10.1175/BAMS-D-12-00066.1.

Portmann, R. W., S. Solomon, and G. C. Hegerl, 2009: Spatial and seasonal patterns in climate change, temperatures, and precipitation across the United States. Proc. Natl. Acad. Sci. USA, 106, https://doi.org/10.1073/pnas.0808533106.

Poumadère, M., C. Mays, S. Le Mer, and R. Blong, 2005: The 2003 heat wave in France: Dangerous climate here and now. Risk Anal., 25, 1483-1494, https://doi.org/10.1111/j.1539-6924.2005.00694.x.

PRISM Climate Group, 2016: Descriptions of PRISM spatial climate datasets for the conterminous United States. Oregon State University Tech. Doc., 22 pp., http://www.prism.oregonstate.edu/ documents/PRISM_datasets.pdf .

Reeves, M. C., and K. E. Bagne, 2016: Vulnerability of cattle production to climate change on U.S. rangelands. USDA Forest Service General Tech. Rep. RMRS-GTR-343, 39 pp., https://www.fs.usda.gov/treesearch/pubs/50907.

Robinson, W. A., R. Reudy, and J. E. Hansen, 2002: General circulation model simulations of recent cooling in the eastcentral United States. J. Geophys. Res., 107, 4748, https:// doi.org/10.1029/2001JD001577.

Rohde, R., and Coauthors, 2013a: A new estimate of the average earth surface land temperature spanning 1975 to 2011. Geoinf. Geostat. Overview, 1, 1000101, https://doi.org/ 10.4172/2327-4581.1000101.

_ aging process. Geoinf. Geostat. Overview, 1, 1000103, https:// doi.org/10.4172/2327-4581.1000103.

Seneviratne, S. I., M. G. Donat, B. Mueller, and L. V. Alexander, 2014: No pause in the increase of hot temperature extremes. Nat. Climate Change, 4, 161-163, https://doi.org/10.1038/ nclimate2145.

Sepulveda, A. J., and Coauthors, 2015: The shifting climate portfolio of the greater Yellowstone area. PLOS ONE, 10, e0145060, https://doi.org/10.1371/journal.pone.0145060.

Shaposhnikov, D., and Coauthors, 2014: Mortality related to air pollution with the Moscow heat wave and wildfire of 2010. Epidemiology, 25, 359-364, https://doi.org/10.1097/EDE.0000000000000090.

Sheridan, S. C., and P. G. Dixon, 2017: Spatiotemporal trends in human vulnerability and adaptation to heat across the United States. Anthropocene, 20, 61-73, https://doi.org/ 10.1016/j.ancene.2016.10.001.

Smith, M. D., 2011: An ecological perspective on extreme climatic events: A synthetic definition and framework to guide future research. J. Ecol., 99, 656-663, https://doi.org/10.1111/ j.1365-2745.2011.01798.x.

Smith, T. T., B. F. Zaitchik, and J. M. Gohlke, 2013: Heat waves in the United States: Definitions, patterns and trends. Climatic Change, 118, 811-825, https://doi.org/10.1007/ s10584-012-0659-2.

Thornton, P. E., S. W. Running, and M. A. White, 1997: Generating surfaces of daily meteorological variables over large regions of complex terrain. J. Hydrol., 190, 214-251, https://doi.org/ 10.1016/S0022-1694(96)03128-9.

_ M. M. Thornton, B. W. Mayer, Y. Wei, R. Davarakonda, R. S. Vose, and R. B. Cook, 2017: Daymet: Daily surface weather grid for North America, version 3. ORNL DAAC, accessed 14 June 2017, https://doi.org/10.3334/ORNLDAAC/ 1328.

Toloo, G., G. FitzGerald, P. Aitken, K. Verrall, and S. Tong, 2013: Are heat warning systems effective? Environ. Health, 12, 27, https://doi.org/10.1186/1476-069X-12-27.

Wang, H., S. Schubert, M. Suarez, J. Chen, M. Hoerling, A. Kumar, and P. Pegion, 2009: Attribution of the seasonality and regionality in climate trends over the United States during 19502000. J. Climate, 22, 2571-2590, https://doi.org/10.1175/ 2008JCLI2359.1. 
Whitman, S., G. Good, E. R. Donoghue, N. Benbow, W. Shou, and S. Mou, 1997: Mortality in Chicago attributed to the July 1995 heat wave. Amer. J. Public Health, 87, 1515-1518, https://doi.org/10.2105/AJPH.87.9.1515.

Wu, Z., H. Lin, J. Li, Z. Jiang, and T. Ma, 2012: Heat wave frequency variability over North America: Two distinct leading modes. J. Geophys. Res., 117, D02102, https://doi.org/10.1029/ 2011JD016908.

Zachariassen, J., K. Zeller, N. Nikolov, and T. McClelland, 2003: A review of the Forest Service remote automated weather station (RAWS) network. USDA Forest Service, General
Tech. Rep. RMRS-GTR-119, 153 pp., https://www.fs.usda. gov/treesearch/pubs/6118.

Zhang, K., R. B. Rood, G. Michailidis, E. M. Oswald, J. D. Schwartz, A. Zanobetti, K. L. Ebi, and M. S. O'Neill, 2012: Comparing exposure metrics for classifying 'dangerous heat' in heat wave and health warning systems. Environ. Int., 46, 23-29, https://doi.org/10.1016/j.envint.2012.05.001.

Zhang, X., G. Hegerl, F. W. Zwiers, and J. Kenyon, 2005: Avoiding inhomogeneity in percentile-based indices of temperature extremes. J. Climate, 18, 1641-1651, https://doi.org/10.1175/ JCLI3366.1. 